\title{
CERTAIN INEQUALITIES FOR CLASSES OF ANALYTIC FUNCTIONS WITH VARYING ARGUMENT OF COEFFICIENTS
}

\section{J. DZIOK}

Abstract. In this paper we introduce new classes of analytic functions with varying argument of coefficients defined by subordination. Several properties like the coefficients inequalities, distortion bounds, subordination theorems and integral means inequalities are investigated. Some consequences of our main results for new or well-known classes of functions are also pointed out.

Mathematics subject classification (2010): 30C45.

Keywords and phrases: Analytic functions, convex functions, varying arguments, subordination, Hadamard product.

\section{REFERENCES}

[1] M. K. Aouf, H. M. Hossen And H.M. SRivastava, Some families of multivalent functions, Comput. Math. Appl., 39 (2000), 39-48.

[2] M. K. Aouf, H. M. SRIVAstava, Some families of starlike functions with negative coefficients, J. Math. Anal. Appl., 203 (1996), 762-790.

[3] A. A. AtTiYA, On a generalization class of bounded starlike functions of complex order, Appl. Math. Comput., 187 (2007), 62-67.

[4] N. E. ChO, O. S. KWON, H. M. SRIVASTAVA, Inclusion relationships and argument properties for certain subclasses of multivalent functions associated with a family of linear operators, J. Math. Anal. Appl., 292 (2004), 470-483.

[5] N. E. Cho, H. M. SRivastava, Argument estimates of certain analytic functions defined by a class of multiplier transformations, Math. Comput. Modelling,, 37 (2003), 39-49.

[6] J. H. ChOI, M. SAIGO, H. M. SRIVASTAVA, Some inclusion properties of a certain family of integral operators, J. Math. Anal. Appl., 276 (2002), 432-445.

[7] J. DZIOK, On some applications of the Briot-Bouquet differential subordination, J. Math. Anal. Appl., 328 (2007), 295-301.

[8] J. DZIOK, H. M. SRivastava, Classes of analytic functions associated with the generalized hypergeometric function, Appl. Math. Comput., 103 (1999), 1-13.

[9] J. DZIOK AND H. M. SRIVAstava, Certain subclasses of analytic functions associated with the generalized hypergeometric function, Integral Transforms Spec. Funct., 14 (2003), 7-18.

[10] J. E. Littlewood, On inequalities in theory of functions, Proc. London Math. Soc., 23 (1925), 481-519.

[11] J.-L. LiU, H. M. SRivastava, Certain properties of the Dziok-Srivastava operator, Appl. Math. Comput., 159 (2004), 485-493.

[12] O. ÖZKan, O. Altintaş, Applications of differential subordination, Appl. Math. Lett., 19 (2006), $728-734$.

[13] J. PATEL, A. K. Mishra, On certain subclasses of multivalent functions associated with an extended fractional differintegral operator, J. Math. Anal. Appl., 332 (2007), 109-122.

[14] R. K RAINA, D. BANSAL, Some properties of a new class of analytic functions defined in terms of a Hadamard product, JIPAM. J. Inequal. Pure Appl. Math., 9 (2008), Article 22.

[15] H. Silverman, Univalent functions with negative coefficients, Proc. Amer. Math. Soc., 51 (1975), $109-116$.

[16] H. Silverman, Univalent functions with varying arguments, Houston J. Math., 7 (1981), 283-287. 
[17] H. SiLVERMAN, A survey with open problems on univalent functions whose coefficients are negative, Rocky Mt. J. Math., 21 (1991), 1099-1125.

[18] H. SiLVERMAN, Integral means for univalent functions with negative coefficients, Houston J. Math., 23 (1997), 169-174.

[19] J. SоKóŁ, On a class of analytic multivalent functions, Appl. Math. Comput., 203 (2008), 210-216.

[20] J. SокóŁ, On some applications of the Dziok-Srivastava operator, Appl. Math. Comput., 201 (2008), 774-780.

[21] H. M. SRIVASTAVA AND M. K. Aouf, A certain fractional derivative operator and its applications to a new class of analytic and multivalent functions with negative coefficients I, J. Math. Anal. Appl. 171 (1992), 1-13, II, J. Math. Anal. Appl., 192 (1995), 673-688.

[22] H. M. SRIVAStaVA, S. OWA, Certain classes of analytic functions with varying arguments, J. Math. Anal. Appl., 136 (1988), 217-228.

[23] H. S. WILF, Subordinating factor sequence for convex maps of the unit circle, Proc. Amer. Math. Soc., 12 (1961), 689-693. 